\title{
Macroinvertebrate community responses to land use: a trait-based approach for freshwater biomonitoring in Mongolia
}

\author{
Oyunchuluun Yadamsuren · John C. Morse • Barbara Hayford • \\ Jon K. Gelhaus • Peter H. Adler
}

Received: 9 January 2019/Revised: 22 February 2020/ Accepted: 5 March 2020/Published online: 20 March 2020

(C) The Author(s) 2020

\begin{abstract}
Land-use practices in Mongolia can lead to environmental degradation and consequently affect the structure and function of biological communities. The main aim of this study was to determine land-use effects on freshwater macroinvertebrate communities based on their response to grazing and mining, using a trait-based approach (TBA). The functional structure of macroinvertebrate communities was examined using 86 categories of 16 traits. A total of 13 physical and chemical variables were significantly different among the levels of land-use intensity. Significant declines in functional diversity were observed with
\end{abstract}

Handling editor: Checo Colón-Gaud

Electronic supplementary material The online version of this article (https://doi.org/10.1007/s10750-020-04220-2) contains supplementary material, which is available to authorized users.

O. Yadamsuren $(\bowtie)$

Department of Biology, School of Mathematics and

Natural Sciences, Mongolian National University of

Education, Ulaanbaatar 210646, Mongolia

e-mail: oyadams@msue.edu.mn

J. C. Morse · P. H. Adler

Department of Plant \& Environmental Sciences, Clemson

University, Clemson, SC 29634-0315, USA

e-mail: jmorse@clemson.edu

P. H. Adler

e-mail: padler@clemson.edu increased land-use intensity. The community weighted mean of 19 trait categories for 11 traits varied significantly among different levels of land-use intensity. Traits were significantly explained by environmental variables across a land-use intensity gradient. Water temperature, gravel, nitrate, silt, and cobble were the main predictor variables and explained $28 \%$ of the total variance of the trait variation. The functional structure of the macroinvertebrate community was strongly related to environmental conditions. The TBA is an important method in assessing disturbance responses in freshwater communities of steppe and taiga regions, such as in Mongolia and other countries in Central Asia and will be useful in finding best management practices for conserving aquatic ecosystems.

\footnotetext{
B. Hayford

Division of Biology, University of Montana, Missoula, MT 59812, USA

e-mail: barbara.hayford@umt.edu

J. K. Gelhaus

Department of Entomology, Academy of Natural Sciences of Drexel University, Philadelphia, PA 19103, USA e-mail: jkg78@drexel.edu

J. K. Gelhaus

Department of Biodiversity, Earth and Environmental Sciences, Drexel University, Philadelphia,

PA 19103, USA
} 
Keywords Trait response - Macroinvertebrates · Land use $\cdot$ Mongolia

\section{Introduction}

Anthropogenic disturbances underlie current global environmental changes, operating with greater intensity than natural disturbances (Vitousek et al., 1997). Lakes and rivers recover from the effect of the majority of natural disturbances relatively quickly compared to that of anthropogenic disturbances (Lake et al., 2000). Catchment land uses by humans cause the most substantial alteration in aquatic biota through interactive effects of nutrient loadings, sedimentation, pollution, erosion, altered channel morphology, and loss of riparian vegetation (Belsky et al. 1999; Quinn \& Stroud, 2002; Scrimgeour \& Kendall, 2003). A number of studies have documented the negative effects of physical habitat alteration due to land use (Wood \& Armitage, 1997) such as reduction of suitable habitats (Chutter, 1969), decline in food sources and quality (Broekhuizen et al., 2001), decrease in the density of certain taxa (Quinn et al., 1992), and loss of biodiversity and changes in community structure (Scrimgeour \& Kendall 2003; Dolédec et al., 2011; Yadamsuren et al., 2015).

Mongolia is a region characterized by steppe ecosystems, where environmental degradation is particularly acute. The quality and quantity of Mongolia's water resources are being degraded by overgrazing and mining (Stubblefield et al., 2005; Shinneman et al., 2009; Maasri \& Gelhaus, 2011). Mongolians have practiced a nomadic lifestyle for more than 4000 years. Livestock husbandry is the mainstay of the Mongolian economy and accounts for $80 \%$ of agricultural output; pasturelands cover $75 \%$ of the total Mongolian territory. As a result of the transition from the socialist system to a market economy in the 1990s, a combination of overgrazing and changes in rotational livestock herding practices have increased the ecological vulnerability of Mongolian grasslands (Altanbagana \& Chuluun, 2010). A total of 61.5 million livestock were reported at the end of 2016 (National Statistical Office of Mongolia-NSO, 2017).

Mis-managed livestock grazing can have direct effects on watersheds, such as plant biomass reduction, alteration of plant-species composition, increased nitrates from dung and urine, soil erosion, soil compaction, loss of physical habitat structure, and increased water turbidity resulting from livestock trampling of shore and in-stream habitats (Reeves \& Champion, 2004). Overgrazing has significant consequences for stream ecosystems, including flooding and loading of sediments and nutrients such as nitrogen and phosphates (Quinn \& Stroud, 2002; Maasri \& Gelhaus, 2011; Hofmann et al., 2015).

Mining has been a rapidly growing industry for the last two decades in Mongolia, accounting for $30 \%$ of the gross national product and $81 \%$ of exports, with several minerals mined, the most important commodities being copper, gold, and coal. The majority of Mongolia's mines are placer, or surface mines, which extract target minerals from alluvial deposits primarily from the sand and gravel of rivers and streams (Javzan, 2004). Many smaller mining activities, including illegal mining, are being undertaken, particularly in streams and riverbeds (Tumurchudur \& Jadambaa, 2012). Mining industries wash deposits mainly with water; $63 \%$ of this is from groundwater and $37 \%$ from surface water (Mun et al., 2008). In placer mining operations, vegetation and fertile topsoil are removed and river-bed morphology is changed (Tumurchudur \& Jadambaa, 2012). Mining increases turbidity and sediment deposition (Wagener \& LaPerriere, 1985); introduces nutrients, especially phosphorus (Stubblefield et al., 2005); and contaminates the water with heavy metals (Inam et al., 2010), all of which degrade physical and chemical habitat quality (Wood \& Armitage, 1997).

Along with physical and chemical assessment, bioassessment is required to manage ecosystem health and conserve biodiversity. Benthic macroinvertebrates are ubiquitous, diverse, and abundant, and they are relatively sedentary, have long life cycles relative to other aquatic organisms, and are responsive to environmental stress; thus, they are useful for biomonitoring (Rosenberg \& Resh, 1993).

There is no Asian-specific bioassessment technique for water quality assessment. Some Asian countries have adjusted North American or European bioassessment methods for water quality, including Mongolia (Morse et al., 2007). Surface water monitoring in Mongolia has been conducted through the Information and Research Institute of Meteorology, Hydrology and Environment (IRIMHE) in Ulaanbaatar at a total of 142 gauging stations on 75 streams and 12 lakes 
throughout Mongolia since the late 1900s. Water regime measurements are being recorded from 120 stations; water chemical samples are being taken from all 142 stations on a regular schedule (Davaa et al., 2007), with water quality monitoring mostly relying on hydrological and chemical monitoring. Benthic macroinvertebrates and plankton are sampled each month from April to October by staff from 64 of the 142 stations and sent to IRIMHE, where they are identified and counted, with the results used to calculate a Family Biotic Index (Hilsenhoff, 1988) for each sampled station.

In recent years, the trait-based approach (TBA) has been described as an alternative to the traditional taxonomic approach for assessing disturbance responses in stream communities (Dolédec \& Statzner, 2010) and has been identified as one of the most promising tools for biomonitoring in freshwater ecosystems (Menezes et al., 2010). A TBA is based on ecological theory, the River Habitat Template Concept, which provides a mechanistic framework for relating community responses to environmental characteristics (Southwood, 1977; Townsend \& Hildrew, 1994). This concept underlying the TBA predicts that traits conferring population resilience (promoting refuge use and recolonization success, such as $r$ selected traits) or resistance (related to survival, such as dormancy or diapause) are more common in temporally variable and spatially homogeneous habitats (Townsend \& Hildrew, 1994).

In a given environment, only taxa possessing certain traits pass through the habitat filter (Keddy, 1992), and those traits can be diagnostic of stressors (Vieira et al., 2006). Species traits can also be used as measures of community functional diversity (Petchey \& Gaston, 2006). In biomonitoring programs, multiple traits are used to determine expected biological status under reference conditions (Vieira et al., 2006) because species traits should vary across environmental gradients (Statzner et al., 2001). Most traits are affected in predictable ways by various types of stressors (Dolédec et al., 2006; Dolédec \& Statzner, 2008). Thus, TBA should be able to determine intensities of disturbance (Gayraud et al., 2003), as do taxonomic approaches, but also to discriminate the effects of different stressors on macroinvertebrate communities (Dolédec et al., 1999). Species traits are less constrained by biogeography (Dolédec et al.,
2011) and are more stable among seasons than is species composition (Culp et al., 2010).

The current surface water quality monitoring system in Mongolia mostly relies on hydrological and chemical monitoring, with no widely accepted national biomonitoring method. Maasri \& Gelhaus (2012) assessed vulnerability of macroinvertebrate communities to climate change, using both taxonomic and functional approaches. They found correlations with $r$-selection, eurythermy, higher tolerance to eutrophication with more scrapers and filter feeders, and frequent meso- and polysaprobic taxa in relation to disturbance. Therefore, TBA may be a suitable biomontoring method for Mongolia and other central Asian countries.

The main objectives of this study were as follows: (1) to examine community responses of macroinvertebrate communities to land-use disturbances using trait-based approaches and (2) to evaluate whether TBA can provide a reliable means for discriminating the effects of different land-use intensities on Mongolian streams. Our hypothesis was that macroinvertebrate functional structure would differ in predictable ways in streams with different levels of land-use intensity according to a priori predictions of the river habitat template. Specifically, we predicted that species traits associated with resilience and resistance to fine-sediment loading and nutrient enrichment would become more common as grazing and mining land-use intensity increased.

\section{Materials and methods}

Study sites

Field sampling occurred in northcentral Mongolia at 42 sites (Fig. 1, Table S1) from the Orkhon, Kharaa, Yeroo, and Tuul Rivers and their tributaries in the Selenge River Basin, which flows northward into Russia and Lake Baikal. The Selenge River Basin is part of the Arctic Basin and is surrounded by the Khentii, Khangai, and Sayan mountain chains, where the average elevation range is $1500-2500 \mathrm{~m}$ a.s.l. The Selenge Basin includes $30.6 \%$ of the water resources for Mongolia, with a 425,245 $\mathrm{km}^{2}$ catchment area, and covers a wide range of ecoregions including taiga, high mountains, forest steppe, and steppe (Tumurchudur \& Jadambaa, 2012). Grazing sites were 


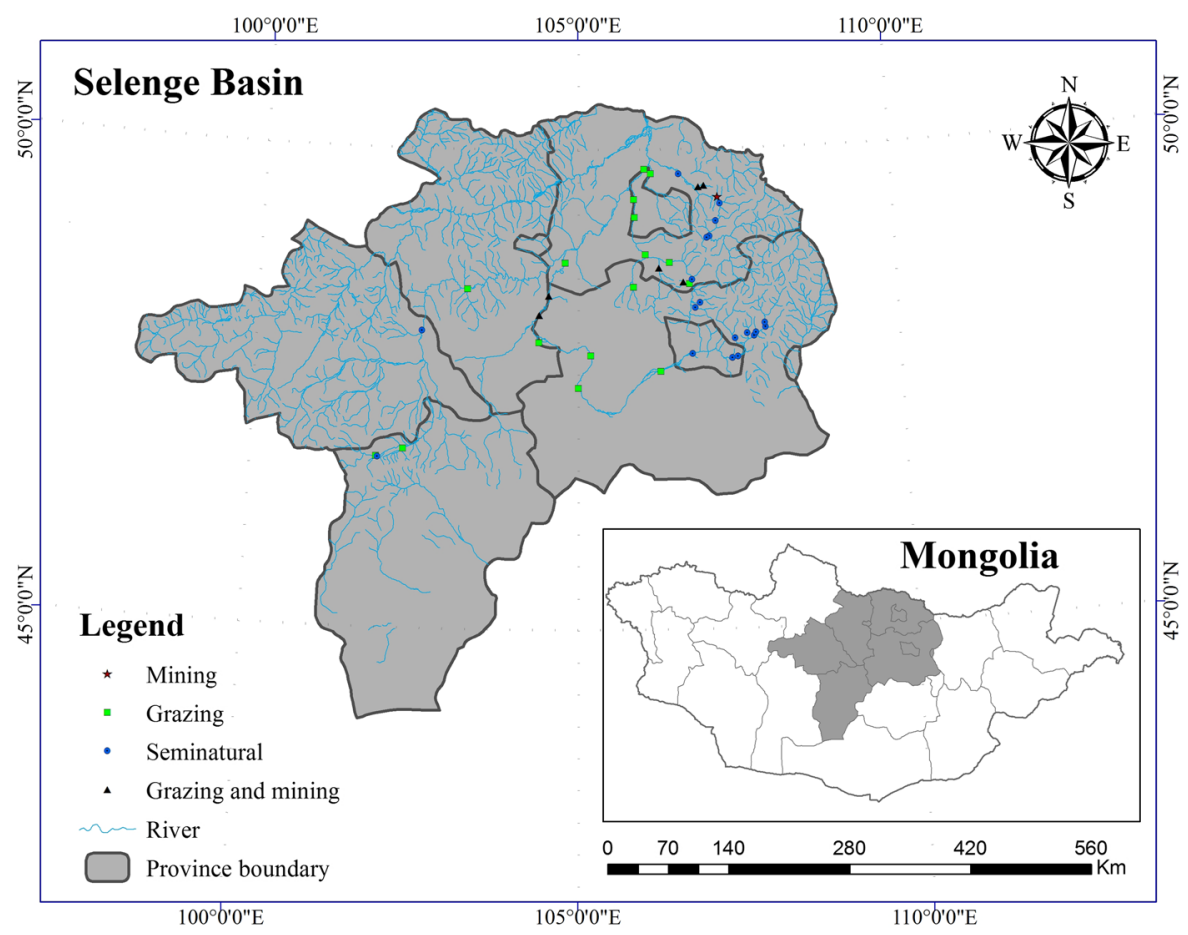

Fig. 1 Map of Mongolia indicating study sites in the Selenge River Basin (shaded area). Land-use categories: seminatural (circle), mining (star), grazing (square), and mining and grazing(triangle)

in pastureland of free-ranging horses and ungulates (cattle, sheep, goats, camels), which were often quite dense. Because Mongolian herders are nomadic, no fences exclude animals from riparian zones or surface waters. Mining activity was present in some study watersheds (Fig. 1, Table S1).

\section{Environmental variables}

The following physical and chemical parameters were measured using a spectrophotometer Hach DR 2800 Field Water Quality Lab in accordance with procedures described in its accompanying manual (Hach, 2007): suspended solids (mg/l), sulfate (mg/ l), phosphate $(\mathrm{mg} / \mathrm{l})$, nitrite $(\mathrm{mg} / \mathrm{l})$, nitrate $(\mathrm{mg} / \mathrm{l})$, ammonium $(\mathrm{mg} / \mathrm{l})$, salinity $(\mathrm{mg} / \mathrm{l})$, water temperature $\left({ }^{\circ} \mathrm{C}\right), \mathrm{pH}$, dissolved oxygen in ppm (DO), conductivity $\left(\mu \mathrm{S} / \mathrm{cm}\right.$ at $20{ }^{\circ} \mathrm{C}$ ), and turbidity in Nephelometric Turbidity Units (NTU) (Table 1). Flow rate was measured at the water surface and at middle and bottom depths at each meter across a stream transect, using a FLO-MATE Electromagnetic Flow Meter (Table 1).
Macroinvertebrate sampling

Forty-two macroinvertebrate samples were collected with a D-net $(500 \mu)$ along a $50-\mathrm{m}$ reach from each site during late-June to mid-July 2011. The sampling protocol followed semiquantitative CPUE methodologies modified from the US EPA's Rapid Bioassessment Protocol (RBP (Barbour et al. 1999). To reduce time and effort for sorting and identification, we used a fixed-count approach that is the preferred subsampling method for the RBP (Barbour et al., 1999). Subsamples of 200 organisms were collected from a composite of 20 kicks or jabs taken from the different microhabitats (riffle, run, and pool) in accordance with their percentage representation within a reach (modified from Barbour et al., 1999).

Samples were fixed in $80 \%$ ethanol, and invertebrates were identified to the lowest possible taxonomic levels. Most insect groups were identified to the genus level, except some water boatmen (Hemiptera: Corixidae), predaceous diving beetles (Coleoptera: Dytiscidae), flies (Diptera), and the non-insect groups, which were identified to only family level (Table S2). 
Table 1 Environmental variable means and standard errors (SE) at seminatural, moderate, and high land-use intensity sites

\begin{tabular}{|c|c|c|c|c|c|c|c|c|}
\hline \multirow[b]{2}{*}{ Variables } & \multicolumn{2}{|c|}{ Seminatural } & \multicolumn{2}{|c|}{ Moderate } & \multicolumn{2}{|l|}{ High } & \multirow[t]{2}{*}{$P$ value } & \multirow[t]{2}{*}{ Post hoc test } \\
\hline & MEAN & SE & MEAN & SE & MEAN & SE & & \\
\hline Nitrite (mg/l) & 0.1 & 2.01 & 4.11 & 2.34 & 0.04 & 2.93 & 0.38 & - \\
\hline Ammonium (mg/l) & 0.03 & 0.01 & 0.06 & 0.01 & 0.26 & 0.01 & $0.001 *$ & $\mathrm{~b}, \mathrm{~b}, \mathrm{a}$ \\
\hline Nitrate $(\mathrm{mg} / \mathrm{l})$ & 1.59 & 0.50 & 2.04 & 0.58 & 3.71 & 0.73 & 0.07 & \\
\hline Sulfate (mg/l) & 20.19 & 4.38 & 37.5 & 5.11 & 26.11 & 6.37 & $0.05^{*}$ & $\mathrm{~b}, \mathrm{a}, \mathrm{ab}$ \\
\hline Phosphate (mg/l) & 0.64 & 0.21 & 1.22 & 0.25 & 0.97 & 0.31 & 0.22 & - \\
\hline Dissolved oxygen (ppm) & 11.36 & 0.28 & 11.37 & 0.32 & 9.17 & 0.41 & $0.0001 *$ & $a, a, b$ \\
\hline Conductivity $(\mu \mathrm{S})$ & 60.52 & 14.37 & 240.42 & 16.74 & 210.17 & 20.87 & $0.001 *$ & $\mathrm{~b}, \mathrm{a}, \mathrm{a}$ \\
\hline Salinity (mg/l) & 0.03 & 0.01 & 0.13 & 0.01 & 0.1 & 0.01 & $0.001 *$ & $\mathrm{~b}, \mathrm{a}, \mathrm{a}$ \\
\hline $\mathrm{PH}$ & 7.93 & 0.12 & 8.33 & 0.14 & 8.25 & 0.17 & 0.08 & - \\
\hline Suspended solid (mg/l) & 10.81 & 10.38 & 43.35 & 12.09 & 179.22 & 15.08 & $0.001 *$ & $c, b, a$ \\
\hline Turbidity (NTU) & 10.77 & 6.47 & 29.23 & 7.54 & 148.43 & 9.4 & $0.001 *$ & $\mathrm{~b}, \mathrm{~b}, \mathrm{a}$ \\
\hline Temperature $\left({ }^{\circ} \mathrm{C}\right)$ & 12.09 & 0.87 & 17.55 & 1.01 & 20.56 & 1.26 & $0.001 *$ & $\mathrm{~b}, \mathrm{a}, \mathrm{a}$ \\
\hline Velocity $(\mathrm{m} / \mathrm{s})$ & 1.48 & 0.09 & 0.76 & 0.11 & 1.73 & 0.15 & $0.005 *$ & $a, b, a$ \\
\hline Depth $(\mathrm{cm})$ & 24.86 & 2.61 & 18.6 & 3.04 & 39.36 & 3.79 & $0.001 *$ & $a, a, b$ \\
\hline Altitude (m) & 1285.47 & 68.44 & 956.14 & 79.73 & 964 & 99.45 & $0.005^{*}$ & $a, b, b$ \\
\hline Vegetation cover $\%$ & 0.81 & 3.77 & 0.84 & 4.39 & 0.71 & 5.48 & 0.16 & - \\
\hline Average vegetation height $(\mathrm{cm})$ & 9.77 & 1.41 & 9.71 & 1.64 & 5.61 & 2.05 & 0.21 & - \\
\hline Bedrock $(\%)$ & 0.01 & 0.005 & 0 & 0.006 & 0 & 0.007 & 0.29 & \\
\hline Boulder (\%) & 0.042 & 0.02 & 0.025 & 0.02 & 0.05 & 0.02 & 0.77 & - \\
\hline Cobble $(\%)$ & 0.31 & 0.02 & 0.05 & 0.02 & 0.13 & 0.03 & $0.001 *$ & $a, b, b$ \\
\hline Gravel $(\%)$ & 0.28 & 0.02 & 0.2 & 0.03 & 0.34 & 0.04 & $0.03^{*}$ & $a b, b, a$ \\
\hline Sand $(\%)$ & 0.16 & 0.03 & 0.23 & 0.04 & 0.24 & 0.05 & 0.21 & - \\
\hline Silt $(\%)$ & 0.04 & 0.009 & 0.06 & 0.01 & 0.04 & 0.01 & 0.32 & - \\
\hline Clay (\%) & 0.02 & 0.07 & 0.05 & 0.08 & 0.29 & 0.1 & 0.08 & - \\
\hline
\end{tabular}

The $P$ values of analysis of variance (ANOVA) and post hoc pairwise comparison using Student's $t$ test for testing statistical differences among sites are given. Statistical differences are denoted with an asterisk. Different letters indicate significant differences among the seminatural, moderate, and high levels of land-use intensity, respectively

A visual habitat assessment (habitat type, substrate type, stream gradient, stream order, erosion extent, and land-use type) method was also modified from the RBP (Barbour et al., 1999). To estimate grazing intensity, a visual assessment of ground cover percentage and a measurement of vegetation height were taken in the riparian zone at 0,10 , and $20 \mathrm{~m}$ from the streambed along 20-m perpendicular transects, using a randomly tossed $1 \mathrm{~m}^{2}$ frame (Daubenmire, 1959). This procedure provided a mean estimate of ground cover percentage and vegetation height for each site (Table 1).

\section{Trait selection}

Species possess traits representing morphological, physiological, behavioral, and ecological features. Two general types of traits are distinguished in current bioassessment programs: biological traits related to life history, mobility, and morphology, and ecological traits related to habitats (Charvet et al., 2000; Dolédec et al., 2000; Statzner et al., 2001; Gayraud et al., 2003).

For 90 taxa, we selected 86 trait categories of 16 traits including body size, life span, voltinism, aquatic stages, reproduction, dissemination, resistant form, respiration, locomotion and substrate relation, feeding habits, food, substrate, current velocity, trophic level, 
temperature preferendum, and saprobity (Table S3) and that were obtainable from available sources (Bis \&Usseglio-Polatera, 2004; Schmidt-Kloiber \& Hering, 2015). We used the trait matrix modified for Mongolian taxa by A. Maasri based on the trait matrix originally developed for European taxa. This made sense since Mongolia has a high proportion of species and genera with widespread Palearctic distributions, and it was also demonstrated to be effective by Maasri $\&$ Gelhaus (2012). These traits were associated with the resilience, resistance, and habitat optima relevant to the environmental gradients of interest. Traits were compiled at the family level for non-insect groups and for a few specimens of Corixidae (Hemiptera), Dytiscidae (Coleoptera), and Ephydridae (Diptera). No complete trait information was available for some insect genera; thus, traits were recorded at the subfamily level for Palpomyia (Ceratopogonidae: Ceratopogoninae) and all Chironomidae (Diptera); and at the family level for the mayflies Acanthametropus (Ephemeroptera: Acanthometropodidae) and Cynigma (Ephemeroptera: Heptageniidae); stoneflies Alloperla, Paraperla, and Haploperla (Plecoptera: Chloroperlidae); caddisflies Chaetopteryx (Trichoptera: Limnephilidae); and dragonflies Anisogomphus (Odonata: Gomphidae); and at the genus level for the rest of the insect taxa (Table S2).

Trait-based analytical approaches can code trait categories using fuzzy-set theory as described by Chevenet et al. (1994). Fuzzy coding accommodates trait variation within a species by recording intermediate affinities. Affinity scoring ranges from 0 to 3 , where 0 indicates no affinity of a species to a given state and 3 indicates that a species has that particular state exclusively.

Taxon-specific affinity scores for a given trait category were treated as relative scores with respect to the sum of all affinity scores that this taxon has in all the categories of that trait. In this way, affinity scores for each taxon and trait category were rescaled between 0 and 1 (Chevenet et al., 1994).

$q_{k}=\frac{a_{k}}{\sum_{k=1}^{h} a_{k}}$ with $q_{k} \geq 0$ and $\sum_{k=1}^{h} q_{k}=1$

$k=$ a trait category, $q_{k}=$ frequency of a trait category, $a_{k}=$ assigned affinity of a trait category, $h=$ total number of categories in a given trait.
Statistical analysis

Study sites were grouped into levels of land-use in the watershed, as minimally ("seminatural"), moderately ("moderate"), and highly ("high") impaired sites defined by Euclidean distances, and Ward's method of divisive hierarchical clustering on environmental variables (Fig. 2) using JMP software version 9.0.2 (SAS Institute Inc., 2010). Hierarchical cluster analysis provides a robust approach to classify sites based on underlying environmental variables (Johnson \& Gage, 1997; Jun et al., 2011), in particular clustering based on the Ward's method performs well in

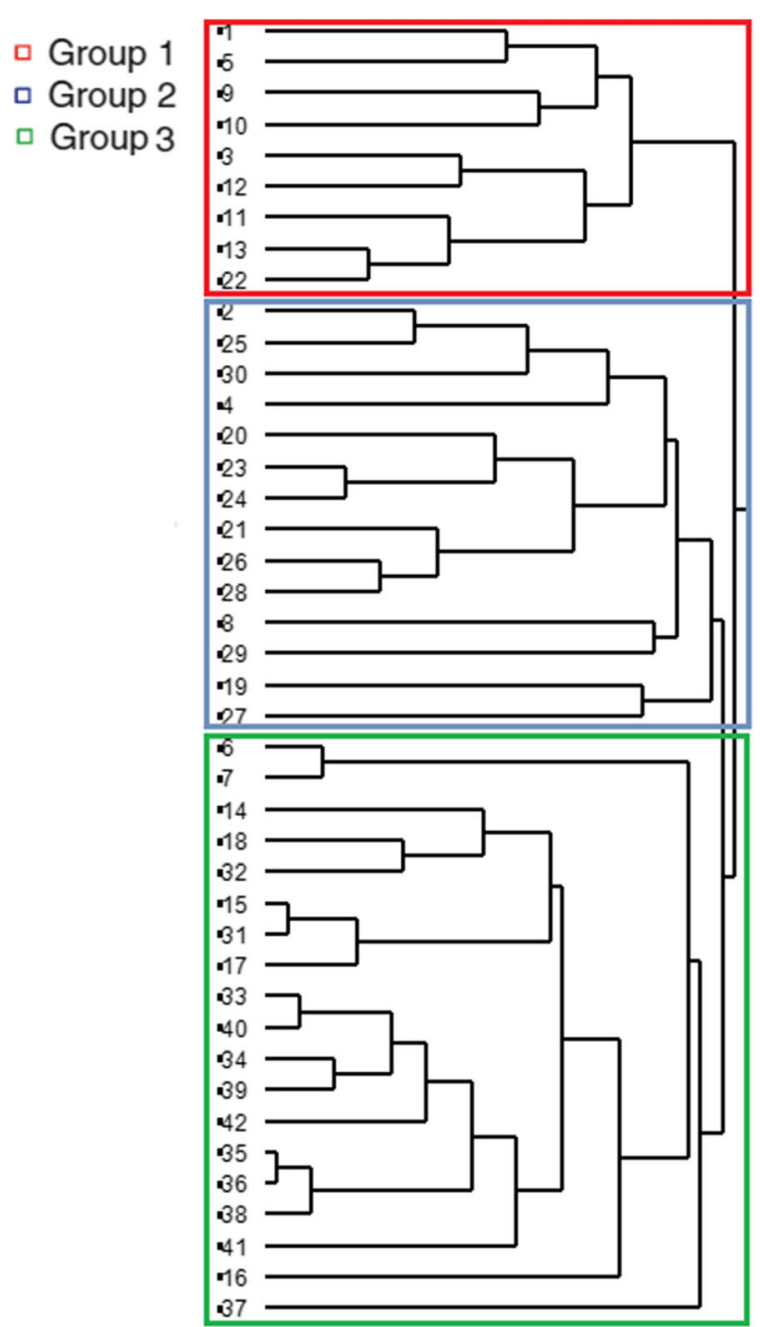

Fig. 2 Dendrogram for site classification on environmental variables, formed by a hierarchical cluster analysis using the ward method. Group 1-low, group 2-moderate, group 3high land-use intensity sites 
classifying objects (Durieux \& Wilderjans, 2019). The Ward's method, which chooses the most similar pair of clusters to merge at each step, is based on the total error sum of squares that will increase to the total within-cluster variance by the minimum possible number of steps (de Amorim, 2015). To test significance among cluster groups, pairwise permutational multivariate analysis of variance (pairwise PERMANOVA; Anderson, 2001) was performed. Permutation tests are used in ecological analyses because widespread problems of non-normal distribution in ecological data may make some parametric tests inappropriate (Borcard et al., 2011). PERMANOVA was implemented using the pairwise.adonis() function in the R "vegan” package (Oksanen et al. 2016) with Bonferroni correction and 1000 permutations.

Functional diversity (FD) was quantified within each site using a functional richness index (Petchey \& Gaston, 2002, 2006) based on trait incidence (present/ absent) using " $f$-diversity" software (Casanoves et al., 2011). This index is the most commonly used and gives a meaningful measure of functional diversity (Pla et al., 2012). The functional diversity index is defined as the total branch length of the dendrogram derived from the functional trait dissimilarity matrix of a community by using cluster analysis (Petchy \& Gaston, 2002, 2006).

$\mathrm{FD}=i^{\prime} * h 2$

$i^{\prime}=$ branch presence/absence row vector, $h 2$ is branch length vector.

Individual trait category differences across the land-use intensity gradients were determined by a community-weighed mean (CWM) trait value. It is a mean trait value weighted by relative abundance (Díaz et al., 2008) and represents the expected functional value of a random community sample (Casanoves et al., 2011).

$\mathrm{CWM}=\sum_{i=1}^{S} p_{i} x_{i}$

$p_{i}$ is relative abundance of ith species, $x_{i}=$ trait value of $i$ th species.

A one-way analysis of variance (ANOVA) was conducted to test whether environmental variables, functional diversity and CWM varied significantly among the land-use categories. A $t$ test was used for pairwise post hoc comparisons. JMP software version
9.0.2 (SAS Institute Inc., 2010) was used for ANOVA and post hoc comparison.

Redundancy analysis (RDA) was performed to relate trait composition of macroinvertebrate communities to variation in the environment among sites using ordistep () function in the R "vegan" package (Oksanen et al. 2016). RDA is a constrained-ordination technique defined by selecting the linear combination of environmental variables that best explain the variation of the dependent matrix (ter Braak \& Verdonschot, 1995) and it is a statistical method typically used to relate community composition to variation in the environment (Borcard, et al., 2011). The frequencies of each trait category per trait were multiplied by the relative abundance of taxa at the site and summed by sites to create a trait-by-site array, and this array was used for RDA analyses (Dolédec et al., 2011). In RDA we used two models: (1) included all 24 environmental variables, (2) included forward selection to determine potential predictors from the environmental variables (Table 1).

PERMANOVA were performed using the adonis() function in the R "vegan" package (Oksanen et al. 2016) with 9999 permutations for testing significance trait variation explained by environmental variables among land-use intensity gradients. RDA analysis and PERMANOVA were performed on R software version 3.0.1 using the "vegan" package (R Development Core Team, 2013).

\section{Results}

The sites were partitioned into three significantly different groups by cluster analysis (pairwise PERMANOVA: $P<0.001$, Fig. 2 ), corresponding to seminatural (low), moderate, and high levels of landuse intensity. The pairwise comparison was significantly different for three groups of clusters only (pairwise PERMANOVA: $P<0.001$ for all pairs of three groups) but was not significant for four (group 1 vs. group $2, P<0.08$ ) or five groups of cluster (group 2 vs. group $3, P<0.11$ and group 2 vs. group 4 , $P<0.47)$. Generally, land-use intensity levels were segregated by grazing intensity for moderate and heavy grazing, either alone or with mining impacts.

A total of 13 physical and chemical variables were significantly different among the levels of land-use intensity (Table 1). Ammonium, sulfate, salinity, 
conductivity, suspended solids, turbidity, and water temperature significantly increased with increased land-use intensity, whereas dissolved oxygen, stream depth, cobble substrates, and elevation were greater in low land-use intensity sites (Table 1). Current velocity and percentage of gravel were lower in moderate landuse intensity sites than in high and low land-use intensity sites (Table 1). Functional diversity was significantly different $(P<0.02)$ among the levels of land-use intensity (Fig. 3). Functional diversity was highest for seminatural sites, intermediate for moderate land-use intensity, and lowest for high land-use intensity (Fig. 3).

Individual traits responded differently to substrate and physical and chemical parameter alteration at the different levels of land-use intensity. The CWM of 19 trait categories for 11 traits was significantly different among sites (Fig. 4). With increased land-use intensity, the frequency of ovoviviparity was significantly greater $(P<0.01)$, whereas the frequency of nonholometabolous taxa (nymph: $P<0.01$ ), aquaticactive dissemination $(P<0.01)$, and predators $(P<0.007)$ was lower. The frequency of taxa with deposit feeding $(P<0.01)$, detritus feeding $(P<0.01)$, aerial spiracle respiration $(P<0.01)$, slow-water velocity optima $(P<0.02)$, mesotrophiclevel optima $(P<0.02)$, eurythermic temperature regime $(P<0.005)$, and mesosaprobism $(\beta$-mesosaprobic: $P<0.0002$; $\alpha$-mesosaprobic: $P<0.001$ ) increased directly with greater land-use intensity. In contrast, the frequency of coarse-substrate habitat (boulders/cobbles/pebbles: $P<0.007$ ), living macrophyte food $(P<0.005)$, and oligotrophic level $(P<0.005)$, fast-water $(P<0.04)$, cold-adapted

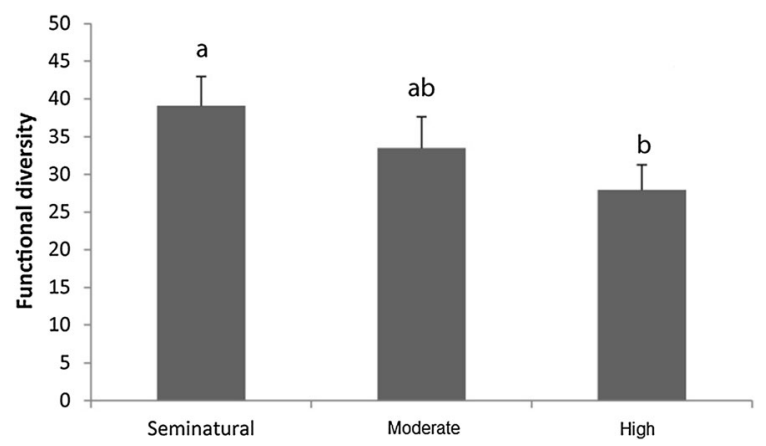

Fig. 3 Functional diversity indices among the three levels of land-use intensity. Standard error of mean taxa richness and pairwise post hoc comparison results are shown with different letters denoting significantly different values
$(P<0.002)$, and xenosaprobic taxa $(P<0.0001)$ decreased with land-use intensity (Fig. 4).

The first model of RDA including all environmental variables showed that traits were significantly explained by land-use intensity (permutations $=9999$, $F=1.7, P<0.000$ ). Constrained variance, which is trait composition explained by environmental variables, represented $64 \%$ of total variance (Table 2). The first two canonical components of RDA accounted for $50 \%$ of the constrained variance. In the second model of RDA, the forward variable selection generated only five variables as the main predictor variables: water temperature $\left(R_{\mathrm{adj}}^{2}=0.05, P<0.003\right)$, gravel $\left(R_{\mathrm{adj}}^{2}=0.10, P<0.002\right)$, nitrate $\left(R_{\mathrm{adj}}^{2}=0.13\right.$, $P<0.027)$, silt $\left(R_{\text {adj }}^{2}=0.16, P<0.013\right)$, and cobble $\left(R_{\text {adj }}^{2}=0.18, P<0.046\right)$. Trait composition explained by these environmental variables represented $28 \%$ of total variance (Table 2) that was significantly explained among the three levels of land-use intensity (permutations $=9999, F=5.22, P<0.000$ ). The first two canonical components of RDA accounted for $23 \%$ of the constrained variance.

The results of the RDA triplot for model 2 show that nitrate level had a negative correlation with percent gravel and cobble substrates, with the first RDA axis accounting for $16 \%$ of the total variation in trait frequency distribution (Fig. 5). Crawlers (Hab-4), shredders (Trop-3), predators (Trop-7), oligosaprobity (Sapr-2), and fast current velocity (Velo-4) correlated with percent course substrate ordination space of the first RDA axis (Fig. 5). In contrast, ovoviviparity (Repr-1), bivoltine (Volt-3), eutrophic taxa (Trop_p3), $\alpha$-mesosaprobic taxa (Sapr-4), and null current velocity optima (Velo-1) were correlated with increased nitrate levels in the negative ordination space of the first RDA axis (Fig. 5). Positive ordination space of the first RDA axis was dominated by seminatural sites while negative ordination space was dominated by moderate land-use intensity sites. The vertical separation of traits in ordination space showed that the second RDA axis demonstrated a much lower proportion of the total variation in trait frequency (Fig. 5). Filter feeder (Trop-5), detritus food (Food-2), and mesotrophic taxa (Trop_p-2) showed a positive influence by water temperature (Fig. 5). Medium body size (Size-4: 1-2 cm), free egg reproduction (Repr-2), resistance in the egg stage (Resi-1), and the presence of an egg life stage (Aqua-1) directly correlated with 

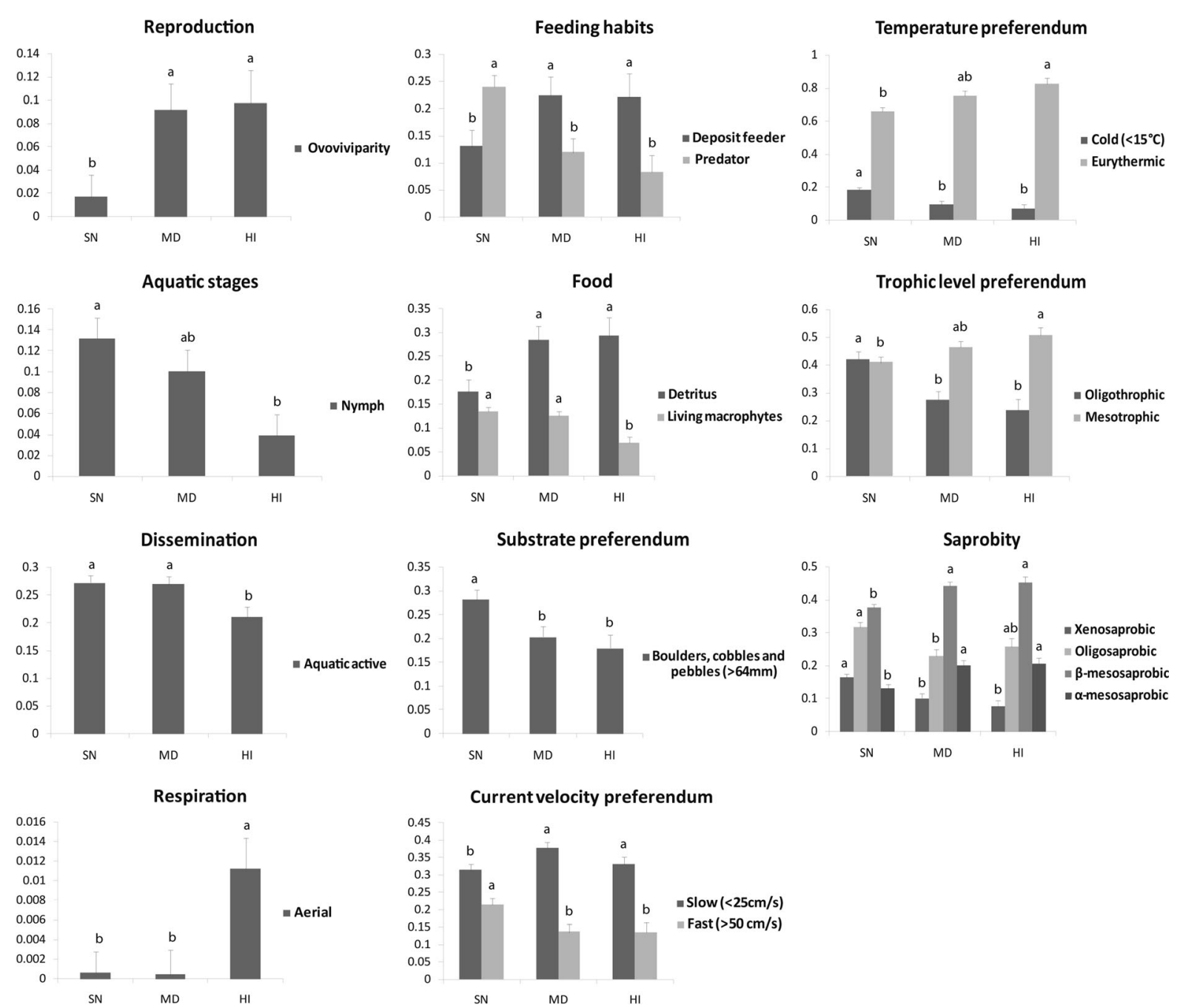

Fig. 4 Comparison of the community weighted mean and standard error of individual trait categories among three levels of land-use intensity. Pairwise post hoc comparison results are shown with different letters ( $a$ and $b$ ) denoting significantly

different values. Only significantly different trait categories among sites are shown. $H I$ high land-use intensity, $M D$ moderate land-use intensity, $S N$ seminatural

percent silt substrate (Fig. 5). Water temperature, silting, and nitrate level were important for discriminating moderate to high levels of land-use intensity from seminatural sites in ordination space as shown on the vertical axis (Fig. 5).

\section{Discussion}

The study sites exhibited significant anthropogenic alteration including increased suspended particles, fine sediments, turbidity, nutrient loading (primarily ammonium, and sulfate in the chemical

measurements), salinity, conductivity, water temperature, and decreased dissolved oxygen (Table 1), indicating water quality degradation. Anthropogenic impacts on stream ecosystems have been well documented. Overgrazing has significant consequences for stream ecosystems, including loading of suspended sediments due to erosion (Hayford \& Gelhaus, 2010; Hartwig et al., 2016), input of nutrients such as nitrogen and phosphate (Vitousek et al., 1997; Carpenter et al., 1998; Maasri \& Gelhaus, 2011) and increased water temperature (Li et al., 1994). Mining causes increased turbidity (from suspended mineral particles), increased sediment deposition (Wagener \& 
Table 2 Summary of redundancy analysis (RDA)

\begin{tabular}{|c|c|c|c|c|c|}
\hline \multirow[t]{2}{*}{ RDA models } & \multicolumn{2}{|l|}{ Model } & & \multicolumn{2}{|c|}{ Environmental variables } \\
\hline & Constrained variance $\%$ & $P$ value & & Cumulative $R_{\text {adj }}^{2}$ & $P$ value \\
\hline Model 1 & 0.64 & $0.000 * * *$ & Water $\mathrm{T}^{\circ} \mathrm{C}$ & 0.05 & 0.003 \\
\hline RDA1 & 0.28 & $0.009 *$ & Gravel \% & 0.10 & 0.002 \\
\hline RDA2 & 0.22 & 0.24 & Nitrate $\mathrm{mg} / \mathrm{l}$ & 0.13 & 0.027 \\
\hline Model 2 & 0.28 & $0.000 * * *$ & Silt \% & 0.16 & 0.013 \\
\hline RDA1 & 0.16 & $0.001 * *$ & Cobble $\%$ & 0.18 & 0.046 \\
\hline RDA2 & 0.07 & $0.04 *$ & & & \\
\hline
\end{tabular}

Models stand for trait composition variance explained by two RDA models 1) All variables included in Tables 1,2) Forward-selected variables: Water $\mathrm{T}^{\circ} \mathrm{C}+$ Gravel + Nitrate + Silt + Cobble. Cumulative $R_{\text {adj }}^{2}$ values are explained by the given variable together with all previously selected variables in the model through forward selection. The order in which the environmental variables are listed corresponds to the order in which they are progressively selected following forward selection

Significance was denoted $* * * P<0.000, * * P<0.001$, and $* P<0.05$

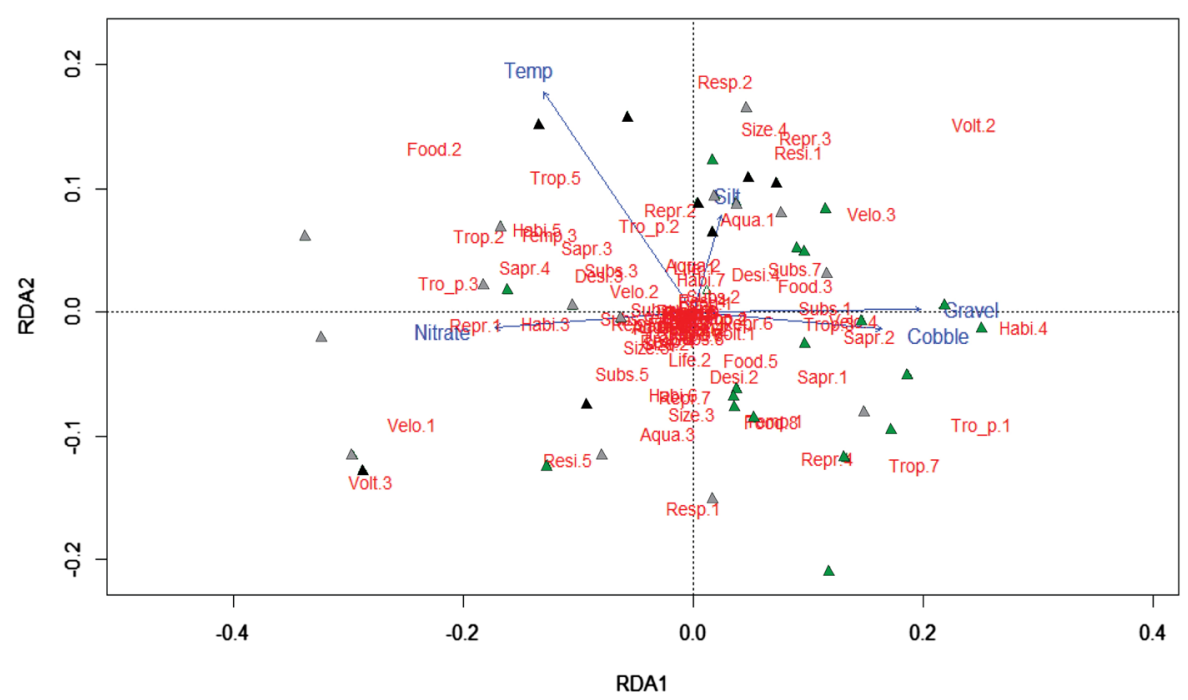

Fig. 5 Ordination triplot of redundancy analysis (RDA) for the macroinvertebrate traits constrained by environmental variables with scaling 1 showing the two first axes of canonical ordination of 42 sites (green triangles = seminatural, gray

LaPerriere, 1985; Hofmann et al., 2015), and metal contamination (Inam et al., 2010; Hofmann et al., 2015). Mining might have resulted in some metal contamination, as indicated by higher conductivity, but determining that requires further analysis. The dominant source of stream water sulfate is chemical weathering of bedrock and its concentration can be elevated after extensive drought conditions (Mayer et al., 2010). Anthropogenic input of sulfate has not been documented in Mongolia (Kelderman \& Batima, 2006). triangles $=$ moderate, black triangles $=$ high level of land-use intensity), 86 trait categories (labeled in red) and 5 selected environmental variables by forward selection (labeled in blue). Trait code descriptions are shown in Table S3

TBA for biomonitoring in Mongolia differentiated between our major land-use categories, demonstrating its utility for biomonitoring. Macroinvertebrate communities at the seminatural sites were functionally more diverse than at sites with high levels of land-use intensity (Fig. 3) and trait compositions were different across land-use gradients (Table 2). Previous studies have shown substantial loss in functional diversity of biological communities for taxa such as macroinvertebrates, fish, birds, and mammals associated with higher land-use intensity (Flynn et al., 2009; Carmona 
et al., 2012; Colzani et al., 2013; Zhang et al., 2013; Wiedmann et al., 2014). Furthermore, our results were consistent with the habitat template concept (Townsend \& Hildrew, 1994) and habitat filtering (Poff, 1997), which predicted that traits associated with population resilience and resistance would be correlated with higher land-use intensity. Most individual traits had a predictable response related to altered environmental conditions, and some of the results supported our predictions that greater population resilience and resistance would be evident in the greater levels of land-use intensity.

Resilience features or traits include high mobility, the prolonged presence of relatively invulnerable life stages, and the ability to regenerate after damage (Townsend \& Hildrew, 1994). With increased levels of land-use intensity, we observed increased ovoviviparity (Glossiphoniidae), bivoltinism, resisting in the egg stage, medium body size (1-2 mm) (Fig. 5), decreased aquatic-active dissemination, and nonholometabolous aquatic stages (Fig. 4) resulting from the increased vulnerability to increased environmental fluctuation. Decreased frequency of predators in the sites with greater levels of land-use intensity (Fig. 4) is possibly explained by biomagnifications due to heavy metal contamination (Dolédec \& Statzner, 2008). Concentrations of metals may have been higher in the sites as evidenced by increased conductivity in those sites (Table 1).

Aquatic habitat degradation may lead to low concentrations of dissolved oxygen (Dodds, 2006) impairing respiration of freshwater invertebrates that obtain oxygen from the water, such as through the integument wall (apneustic invertebrates) and the tracheal or spiracular gills (Jesus, 2008) and oxygen uptake may require a specialized technique in higher temperature and low flow (Statzner \& Bêche, 2010). Increased frequency of taxa such as Helophorus sp., Sigara sp., Micronecta sp., and Crenitis sp. with specialized respiration adaptations like aerial spiracles was related to a decreased level of dissolved oxygen at high land-use intensity sites (Fig. 4). By obtaining oxygen from the vascular tissue of aquatic plants or by penetrating the water surface, air-breathing insects can withstand oxygen-depleted, stagnant water (Pedersen \& Colmer, 2012). Increased deposit feeders and filterers (Figs. 4, 5) were indirect evidence of the high amount of deposited and suspended particulate organic matter (FPOM and CPOM) available in stream beds and in the water column resulting from nutrient loading in agricultural streams (Carlson et al., 2013).

According to the forward selection of RDA variables, water temperature, nitrate, and substrates were the main predictors for variation in trait composition (Table 2). Livestock grazing may impact watersheds by increasing nitrate levels from soil erosion and deposition of livestock dung and urine (Reeves \& Champion, 2004). Elevated nitrate concentrations contribute to organic pollution (de Jonge et al., 2002) and may be toxic to aquatic organisms (Camargo et al., 2005). Water temperature and chemical parameters including nitrate level can affect taxonomic and trait structure of stream organisms (Hawkins et al., 1997; Kuzmanovic et al., 2017). Similarly, our findings indicate that an increased frequency of taxa tolerant of pollution (e.g., eurythermic, eutrophic, and $\alpha$-mesosaprobic taxa) and a decreased frequency of taxa intolerant to pollution (e.g., xenosaprobic and oligosaprobic taxa) resulted from increased nitrate level due to land-use activities such as grazing (Fig. 5).

Substrate size heterogeneity provides refuge from disturbance and predation, and promotes a greater variety of food sources, thereby playing an important role in trait variation, specifically traits related to feeding habits, locomotion, and substrate selection (Duan et al., 2008; Milesi et al., 2016). Grazing and mining activities increase sediment deposition and turbidity by input of suspended mineral particles that degrade habitat quality (Hayford \& Gelhaus, 2010; Hofmann et al., 2015). Fine-sediment loads affect benthic macroinvertebrate communities in several different ways, such as filling interstitial spaces among stone and altering suitability of substrate for some taxa (Richard \& Bacon, 1994) and reducing food availability (Graham, 1990). Our results indicate that differences in land-use intensity were associated with habitat differences that subsequently modified the macroinvertebrate community. For example, increased fine sediment loading and silting in the moderate to high level of land-use intensity sites favored filter feeders, deposit feeders, and burrowers (Fig. 5).

TBA discriminated seminatural sites from sites with greater levels of land-use intensity, using mixed genus- and family-level resolution and provided a mechanistic interpretation for the underlying changes 
in community structure due to land use. Another advantage of TBA is that it includes detection of different types of stressors and impacts of land use and consistent community descriptors less constrained by biogeography (Menezes et al., 2010), a benefit for bioassessment across an area with such a large spatial scale as Mongolia. However, one constraint of this study is that natural variation in habitat (e.g., variation of minerals, acidity in water or rainfall, climate, elevation, and geology among catchments, ecoregions, or basins) rather than land-use modification may affect community assembly (Heino et al., 2007, 2013). In our study, most of the least-grazed sites we encountered were at higher elevations, but a few higher-elevation sites were strongly grazed. Elevation was not the best predictor variable of trait variation as the result of forward selection of RDA, but there was a correlation between elevation and water temperature $(r=-0.4 ; P<0.002)$ which was the first environmental variable identified through forward selection in RDA (Table 2). Thus, elevation could be a confounding factor of variation in some traits such as cold-water adaptation (Hayford \& Gelhaus, 2010).

Constraints on the widespread use of TBA include the inconsistency of trait terms, a need for descriptions of trait modalities applicable across taxa, and inadequate knowledge of trait differences (Culp et al., 2010). Lack of ecological and biological knowledge has resulted in incomplete trait information, requiring extrapolation of traits from confamilials (Lenat \& Resh, 2001) or from a few representative species or genera, which have been used to generalize those traits for entire genera or families. The "trait syndrome" or inferring the co-occurrence of phylogenetically constrained traits in closely related taxa is another issue (Poff et al., 2006); phylogenetically decoupled and more plastic traits are more robust for bioassessment (Vieira et al., 2006). Despite these constraints, our results were effective in detecting habitat degradation. Future improvements in TBA addressing these limitations will improve an already-effective method in biological assessment and monitoring.

One weakness of this study was the use of a fixedcount field method that may lead to a bias for picking larger specimens over smaller specimens. However, the field crew had over fifteen years of experience in this method and was trained in finding small invertebrates such as chironomids, reducing the chance of large-specimen bias. The method was used, in part, to maintain methods similar to those used in Mongolia over the past twenty years. Also, we used this method due to field constraints including the lack of roads in many regions, leading to long travel time. Long travel times significantly reduced the time for sampling at each site. The poor suspension systems in the field vehicles traversing a landscape with few to no roads increased the likelihood of damaging specimens, which led the field crew to reduce the volume of samples by sorting and picking in the field. The loss of community data information during sample processing is greater with the fixed-count approach. Therefore, to deal with this potential problem, we used presence/ absence data for functional diversity and relative abundance for CWM and RDA, which is a standard practice (Davis et al., 2006; Maasri \& Gelhaus, 2012).

A trait-based approach (TBA) is an alternative to traditional approaches (TAs) and is a promising method to reveal changes in communities due to disturbance and to define the structure of biological communities (Dolédec et al., 1999, 2008; Charvet et al., 2000; Usseglio-Polatera et al., 2000; Statzner et al., 2001; Gayraud et al., 2003; Bady et al., 2005; Poff et al., 2006). TBA was developed in Europe and has been an increasingly applied biomonitoring practice there (Dolédec et al., 1999, 2000, 2008; Charvet et al., 2000, Usseglio-Polatera et al., 2000; Statzner et al., 2004; Gayraud et al., 2003; Díaz et al., 2008; Menezes et al., 2010; Feio \& Dolédec, 2012). TBA has also been explored in North America (e.g., Poff et al., 2006; Vieira et al., 2006), Australia (Chessman \& Royal, 2004), New Zealand (Dolédec et al., 2006, 2011), and China (Zhang et al., 2013; He et al., 2015). Here we show its effective use for bioassessment in Mongolia and potentially other parts of Central Asia.

This study is important in the context of environmental and climatic change in Central Asia. The combination of ongoing land and water degradation multiplied by climate change will almost certainly result in substantial ecological degradation with subsequent impacts on ecosystem services. Desertification in Central Asian grasslands is predicted to increase, causing widespread economic impact (Millennium Ecosystem Assessment, 2005). For example, watersheds in the arid and semi-arid regions of Mongolia are especially vulnerable to the effects of land-cover changes (Jordan et al., 2018). This study suggests that a TBA with emphasis on the functional attributes of macroinvertebrates and their association with ecosystem properties, especially 
functional-feeding and functional-habit attributes, are applicable to water quality monitoring in the region, providing valuable information for land-use management to maintain ecosystem functions and water provisioning services critical for the survival of rural communities and economies.

Acknowledgements We thank Dr. Bryan L. Brown (Virginia Polytechnic Institute and State University) and Dr. Saara DeWalt (Clemson University) for their helpful comments on an earlier version of this paper and data analysis, Dr. Alain Maasri (The Leibniz Institute of Freshwater Ecology and Inland Fisheries) for providing the trait database modified from a European trait database, Bolortsetseg Erdene (Drexel University), and Tumurtsooj Dashtogtokh (The Information and Research Institute of Meteorology, Hydrology and Environment, Mongolia) for their excellent field assistance. We gratefully acknowledge the generous support of the US National Science Foundation (DEB-BSI \#0206674, "Survey and Inventory of the Aquatic Macroinvertebrates of the Selenge River, Mongolia" to J. Gelhaus, J. Morse, B. Hayford), (DEBBSI \#0743732, "Survey and Inventory of the Aquatic Macroinvertebrates of the Altai and Hangai Mountain drainages, Mongolia", to J. Gelhaus, J. Morse, C. R. Nelson), and (DEB-BS\&I \#0816910, "An Ecological Guild-Based Biodiversity Inventory and Survey of the Aquatic Non-biting Midges (Diptera: Chironomidae) of the Altai and Hangai Mountain Drainages, Mongolia" to B. Hayford). Also, we are extremely grateful for the NSF Macrosystems award (grant no. 1442595) and the office of Research and Innovation at the Mongolian National University of Education for their additional support in covering publication costs.

Open Access This article is licensed under a Creative Commons Attribution 4.0 International License, which permits use, sharing, adaptation, distribution and reproduction in any medium or format, as long as you give appropriate credit to the original author(s) and the source, provide a link to the Creative Commons licence, and indicate if changes were made. The images or other third party material in this article are included in the article's Creative Commons licence, unless indicated otherwise in a credit line to the material. If material is not included in the article's Creative Commons licence and your intended use is not permitted by statutory regulation or exceeds the permitted use, you will need to obtain permission directly from the copyright holder. To view a copy of this licence, visit http://creativecommons.org/licenses/by/4.0/.

\section{References}

Altanbagana, M. \& T. Chuluun, 2010. Vulnerability assessment of Mongolian social-ecological systems. In Renchin, T. (eds), The Proceedings of the 4th international and national workshop: Applications of geo-informatics for natural resources and the environment. National University of Mongolia, Ulaanbaatar: 1-11.
Anderson, M. J., 2001. A new method for non-parametric multivariate analysis of variance. Austral Ecology 26: 32.

Bady, P., S. Dolédec, C. Fesl, S. Gayraud, M. Bacchi \& F. Schöll, 2005. Use of invertebrate traits for the biomonitoring of European large rivers: the effects of sampling effort on genus richness and functional diversity. Freshwater Biology 50: 159-173.

Barbour, M. T., J. Gerritsen, B. Snyder \& J. Stribling, 1999. Rapid Bioassessment Protocols for Use in Streams and Wadeable Rivers: Periphyton, Benthic Macroinvertebrates and Fish. US Environmental Protection Agency, Washington.

Belsky, A. J., A. Matzke \& S. Uselman, 1999. Survey of livestock influences on stream and riparian ecosystems in the western United States. Journal of Soil and Water Conservation 54: 419-431.

Bis, B. \& P. Usseglio-Polatera, 2004. Species trait analysis. http://www.eu-star.at/pdf/Deliverable_N2.pdf Accessed 3 October 2010.

Bonada, N., S. Dolédec \& B. Statzner, 2007. Taxonomic and biological trait differences of stream macroinvertebrate communities between Mediterranean and temperate regions: implications for future climatic scenarios. Global Change Biology 13: 1658-1671.

Borcard, D., F. Gillet \& P. Legendre, 2011. Numerical Ecology with R. Springer, New York.

Broekhuizen, N., S. Parkyn \& D. Miller, 2001. Fine sediment effects on feeding and growth in the invertebrate grazers Potamopyrgus antipodarum (Gastropoda, Hydrobiidae) and Dealeatidiumsp. (Ephemeroptera, Leptophlebiidae). Hydrobiologia 457: 125-132.

Camargo, J. A., A. Alonso \& A. Salamanca, 2005. Nitrate toxicity to aquatic animals: a review with new data for freshwater invertebrates. Chemosphere 58: 1255-1267.

Carlson, P. E., R. K. Johnson \& B. G. McKie, 2013. Optimizing stream bioassessment: habitat, season, and the impacts of land use on benthic macroinvertebrates. Hydrobiologia 704: 363-373.

Carmona, C. P., F. M. Azcárate, F. Bello, H. S. Ollero, J. Lepš \& B. Peco, 2012. Taxonomical and functional diversity turnover in Mediterranean grasslands: interactions between grazing, habitat type and rainfall. Journal of Applied Ecology 49: 1084-1093.

Carpenter, S. R., N. F. Caraco, D. L. Correll, R. W. Howarth, A. N. Sharpley \& V. H. Smith, 1998. Nonpoint pollution of surface waters with phosphorus and nitrogen. Ecological applications 8: 559-568.

Casanoves, F., L. Pla, J. A. Di Rienzo \& S. Díaz, 2011. F Diversity: a software package for the integrated analysis of functional diversity. Methods in Ecology and Evolution 2: 233-237.

Charvet, S., B. Statzner, P. Usseglio-Polatera \& B. Dumont, 2000. Traits of benthic macroinvertebrates in semi-natural French streams: an initial application to biomonitoring in Europe. Freshwater Biology 43: 277-296.

Chessman, B. C. \& M. J. Royal, 2004. Bioassessment without reference sites: use of environmental filters to predict natural assemblages of macroinvertebrates. Journal of the North American Benthological Society 23: 599-615.

Chevenet, F., S. Dolédec \& D. Chessel, 1994. A fuzzy coding approach for the analysis of long-term ecological data. Freshwater Biology 31: 295-309. 
Chutter, F. M., 1969. The effects of silt and sand on the invertebrate fauna of streams and rivers. Hydrobiologia 34: 57-76.

Colzani, E., T. Sequeira, M. T. Surlano \& F. O. Roque, 2013. Responses of aquatic insect functional diversity to landscape change in Atlantic forest. Biotropica 45: 343-350.

Culp, J. M., D. G. Armanini, M. J. Dunbar, J. M. Orlofske, N. L. Poff, A. I. Pollard, A. G. Yates \& G. C. Hose, 2010. Incorporating traits in aquatic biomonitoring to enhance causal diagnosis and prediction. Integrated Environmental Assessment and Management 7: 187-197.

Daubenmire, R., 1959. A canopy-coverage method of vegetational analysis. Northwest Science 33: 43-64.

Davaa, G., D. Oyunbaatar \& M. Sugita, 2007. Surface water of Mongolia. Environmental Book of Mongolia 2006: 55-82.

Davis, J., P. Horwitz, R. Norris, B. Chessman, M. McGuire \& B. Sommer, 2006. Are river bioassessment methods using macroinvertebrates applicable to wetlands? Hydrobiologia 572: 115-128.

de Amorim, R. C., 2015. Feature relevance in ward's hierarchical clustering using the $\mathrm{L} p$ norm. Journal of Classification 32: 46-62.

de Jonge, V. N., M. Elliott \& E. Orive, 2002. Causes, historical development, effects and future challenges of a common environmental problem: eutrophication. Hydrobiologia 475(476): 1-19.

Díaz, A. M., M. L. S. Alonso \& M. R. V. A. Gutierrez, 2008. Biological traits of stream macroinvertebrates from a semiarid catchment: patterns along complex environmental gradients. Freshwater Biology 53: 1-21.

Dodds, W. K., 2006. Eutrophication and trophic state in rivers and streams. Limnology and Oceanography 51: 671-680.

Dolédec, S. \& B. Statzner, 2008. Invertebrate traits for the biomonitoring of large European rivers: an assessment of specific types of human impact. Freshwater Biology 53: 617-634.

Dolédec, S. \& B. Statzner, 2010. Responses of freshwater biota to human disturbances: contribution of J-NABS to developments in ecological integrity assessments. Journal of the North American Benthological Society 29: 286-311.

Dolédec, S., B. Statzner \& M. Bournard, 1999. Species traits for future biomonitoring across ecoregions: patterns along a human-impacted river. Freshwater Biology 42: 737-758.

Dolédec, S., J. M. Oliver \& B. Statzner, 2000. Accurate description of the abundance of taxa and their biological traits in stream invertebrate communities: the effect of spatial and taxonomic resolution. Hydrobiologia 148: 25-43.

Dolédec, S., N. Phillips, M. Scarsbrook, R. H. Riley \& C. R. Townsend, 2006. Comparison of structural and functional approaches to determining land-use effects on grassland stream invertebrate communities. Journal of the North American Benthological Society 25: 44-60.

Dolédec, S., N. Phillips \& C. Townsend, 2011. Invertebrate community responses to land use at a broad spatial scale: trait and taxonomic measures compared in New Zealand Rivers. Freshwater Biology 56: 1670-1688.

Duan, X., Z. Wang \& S. Tian, 2008. Effect of streambed substrate on macroinvertebrate biodiversity. Frontiers of Environmental Science \& Engineering in China 2: 122-128.

Durieux, J. \& T. F. Wilderjans, 2019. Partitioning subjects based on high-dimensional fMRI data: comparison of several clustering methods and studying the influence of ICA data reduction in big data. Behaviormetrika 46: 1-41.

Feio, M. J. \& S. Dolédec, 2012. Integration of invertebrate traits into predictive models for indirect assessment of stream functional integrity: a case study in Portugal. Ecological Indicators 15: 236-247.

Flynn, D. F., M. Gogol-Prokurat, T. Nogeire, N. Molinari, B. T. Richers, B. B. Lin, N. Simpson, M. M. Mayfield \& F. deClerck, 2009. Loss of functional diversity under land use intensification across multiple taxa. Ecology Letters 12: 22-33.

Gayraud, S., B. Statzner, P. Bady, A. Haybachp, F. Scholl, P. Usseglio-Polatera \& M. Bacchi, 2003. Invertebrate traits for the biomonitoring of large European rivers: an initial assessment of alternative metrics. Freshwater Biology 48: 2045-2064.

Graham, A., 1990. Siltation of stone-surface periphyton in rivers by clay-sized particles from low concentrations in suspension. Hydrobiologia 199: 107-115.

Hach., 2007. DR2800 Spectophotometer procedures manual. https://www.hach.com/asset-get.download.jsa?id= 7639982436 Accessed 30 March 2011.

Hartwig, M., M. Schäffer, P. Theuring, S. Avlyush, M. Rode \& D. Borchardt, 2016. Cause-effect-response chains linking source identification of eroded sediments, loss of aquatic ecosystem integrity and management options in a steppe river catchment (Kharaa, Mongolia). Environmental Earth Sciences 75: 855.

Hawkins, C. P., J. N. Hogue, L. M. Decker \& J. W. Feminella, 1997. Channel morphology, water temperature, and assemblage structure of stream insects. Journal of the North American Benthological Society 16: 728-749.

Hayford, B. \& J. Gelhaus, 2010. The relationship between grazing, erosion and adult aquatic insects in streams in Mongolia. Mongolian Journal of Biological Sciences 8: 27-39.

He, F., W. Jiang, T. Tang \& Q. Cai, 2015. Assessing impact of acid mine drainage on benthic macroinvertebrates: can functional diversity metrics be used as indicators? Journal of Freshwater Ecology 30: 513-524.

Heino, J., H. Mykrä, J. Kotanen \& T. Muotka, 2007. Ecological filters and variability in stream macroinvertebrate communities: do taxonomic and functional structures follow the same path? Ecography 30: 217-230.

Heino, J., D. Schmera \& T. Eros, 2013. A macroecological perspective of trait patterns in stream communities. Freshwater Biology 58: 1539-1555.

Hilsenhoff, W. L., 1988. Rapid field assessment of organic pollution with a family-level biotic index. Journal of the North American Benthological Society 7: 65-68.

Hofmann, J., D. Karthe, R. Ibisch, M. Schäffer, S. Avlyush, S. Heldt \& A. Kaus, 2015. Initial characterization and water quality assessment of stream landscapes in northern Mongolia. Water 27: 3166-3205.

Inam, E., S. Khantotong, K. Kim, B. Tumendemberel, S. Erdenetsetseg \& T. Puntsag, 2010. Geochemical distribution of trace element concentrations in the vicinity of Boroo Gold Mine, Mongolia. Environmental Geochemistry and Health 33 : 57-59.

Javzan, C., 2004. Study of Tuul River pollution. Geo-ecology Issues in Mongolia 1: 213-219. 
Jesus, T. M., 2008. Ecological, anatomical and physiological traits of benthic macroinvertebrates: their use on the health characterization of freshwater ecosystems. Limnetica 27: 079-092.

Johnson, L. \& S. Gage, 1997. Landscape approaches to the analysis of aquatic ecosystems. Freshwater Biology 37: 113-132.

Jordan, G., S. Goenster-Jordan, G. J. Lamparter, B. Ulziisuren, N. Soninkishig, E. Schlecht \& A. Buerkert, 2018. Water use in agro-pastoral livelihood systems within the Bulgan River watershed of the Altay Mountains, Western Mongolia. Agriculture, Ecosystems \& Environment 251: 180-193.

Jun, Y. C., N. Y. Kim, S. J. Kwon, S. C. Han, I. C. Hwang, J. H. Park, D. H. Won, M. S. Byun, H. Y. Kong, J. E. Lee \& S. J. Hwang, 2011. Effects of land use on benthic macroinvertebrate communities: comparison of two mountain streams in Korea. Journal of Limnology 47: 35-49.

Keddy, P. A., 1992. Assembly and response rules: two goals for predictive community ecology. Journal of Vegetation Science 3: 157-164.

Kelderman, P. \& P. Batima, 2006. Water quality assessment of rivers in Mongolia. Water science and technology 53: 111-119.

Kuzmanovic, M., S. Dolédec, N. de Castro-Catala, A. Ginebreda, S. Sabater, I. Muñoz \& D. Barceló, 2017. Environmental stressors as a driver of the trait composition of benthic macroinvertebrate assemblages in polluted Iberian rivers. Environmental research 156: 485-493.

Lake, P. S., M. A. Palmer, P. Biro, J. Cole, A. P. Covich, C. Dahm, J. Gibert, W. Goedkoop, K. Martens \& J. O. S. Verhoeven, 2000. Global change and the biodiversity of freshwater ecosystems: impacts on linkages between above-sediment and sediment biota: All forms of anthropogenic disturbance - changes in land use, biogeochemical processes, or biotic addition or loss - not only damage the biota of freshwater sediments but also disrupt the linkages between above-sediment and sediment-dwelling biota. BioScience 50: 1099-1107.

Lenat, D. R. \& V. H. Resh, 2001. Taxonomy and stream ecology - the benefits of genus-and species-level identifications. Journal of the North American Benthological Society 20: 287-298.

Li, H. W., G. A. Lamberti, T. N. Pearsons, C. K. Tait, J. L. Li \& J. C. Buckhouse, 1994. Cumulative effects of riparian disturbances along high desert trout streams of the John Day Basin, Oregon. Transactions of the American Fisheries Society 123: 627-640.

Maasri, A. \& J. Gelhaus, 2011. The new era of livestock production in Mongolia: consequences on streams of the Great Lakes Depression. Science of the Total Environment 409: 4841-4846.

Maasri, A. \& J. Gelhaus, 2012. Stream invertebrate communities of Mongolia: current structure and expected changes due to climate change. Aquatic Biosystems 8: 1-13.

Mayer, B., J. B. Shanley, S. W. Bailey \& M. J. Mitchell, 2010. Identifying sources of stream water sulfate after a summer drought in the Sleepers River watershed (Vermont, USA) using hydrological, chemical, and isotopic techniques. Applied Geochemistry 25: 747-754.
Menezes, S., D. J. Baird \& A. M. Soares, 2010. Beyond taxonomy: a review of macroinvertebrate trait-based community descriptors as tools for freshwater biomonitoring. Journal of Applied Ecology 47: 711-719.

Milesi, S. V., S. Dolédec \& A. S. Melo, 2016. Substrate heterogeneity influences the trait composition of stream insect communities: an experimental in situ study. Freshwater Science 35: 1321-1329.

Millennium Ecosystem Assessment, 2005. Ecosystems and Human Well-Being: Desertification Synthesis. World Resources Institute, Washington, DC.

Morse, J. C., Y. J. Bae, G. Munkhjargal, N. Sangpradub, K. Tanida, T. S. Vshivkova, B. Wang, L. Yang \& C. M. Yule, 2007. Freshwater biomonitoring with macroinvertebrates in East Asia. Frontiers in Ecology and the Environment 5: 33-42.

Mun, Y., I. H. Ko, L. Janchivdorj, B. Gomboev, C. I. Kang \& C. Lee, 2008. Integrated Water Management Model on the Selenge River Basin: Status Survey and Investigation (Phase I). Korea Environment Institute, Seoul.

National Statistical Office of Mongolia, 2017. Livestock consensus. http://www.nso.mn. Accessed on 16 June 2017.

Oksanen J., J.G. Blanchet, R.Kindt,P. Legendre, P. R. Minchin, P. B. O'Hara, G.L. Simpson, P. Solymos, M. H. H. Stevens \& H. Wagner, 2016.Vegan:Community Ecology Package. $\mathrm{R}$ package version 2.3-5. http://CRAN.R-project.org/ package $=$ vegan.

Pedersen, O. \& T. D. Colmer, 2012. Physical gills prevent drowning of many wetland insects, spiders and plants. Journal of Experimental Biology 215: 705-709.

Petchey, O. L. \& K. J. Gaston, 2002. Functional diversity (FD), species richness and community composition. Ecology Letters 5: 402-411.

Petchey, O. L. \& K. J. Gaston, 2006. Functional diversity: back to basics and looking forward. Ecology Letters 9: 741-758.

Pla, L., E. Casanoves \& J. DeRienzo, 2012. Quantifying Functional Biodiversity. Springer, New York.

Poff, N. L., 1997. Landscape filters and species traits: towards mechanistic understanding and prediction in stream ecology. Journal of the North American Benthological Society 16: 391-409.

Poff, N. L., J. D. Olden, N. K. Vieira, D. S. Finn, M. P. Simmons \& B. C. Kondratieff, 2006. Functional trait niches of North American lotic insects: traits-based ecological applications in light of phylogenetic relationships. Journal of the North American Benthological Society 25: 730-755.

Quinn, J. M. \& M. J. Stroud, 2002. Water quality and sediment and nutrient export from New Zealand hill-land catchments of contrasting land use. New Zealand Journal of Marine and Freshwater Research 36: 409-429.

Quinn, J. M., R. Davies-Colley, C. Hickey, M. Vickers \& P. Ryan, 1992. Effects of clay discharges on streams. Hydrobiologia 248: 235-247.

R Development Core Team, 2013. R: A Language and Environment for Statistical Computing. R Foundation for Statistical Computing, Vienna.

Reeves, P. \& P. Champion, 2004. Effects of livestock grazing on wetlands: Literature review. National Institute of Water \& Atmospheric Research Ltd (NIWA) Client report. Hamilton. 
Rosenberg, D. M. \& V. H. Resh, 1993. Freshwater Biomonitoring and Benthic Macroinvertebrates. Chapman \& Hall, New York.

SAS Institute Inc., 2010. JMP, Version 9.0 SAS Institute Inc., Cary, NC, 1989-2010.

Schmidt-Kloiber, A. \& D. Hering, 2015. www.freshwaterecology.info - an online tool that unifies, standardizes and codifies more than 20,000 European freshwater organisms and their ecological preferences. Ecological Indicators 53: 271-282.

Scrimgeour, G. J. \& S. Kendall, 2003. Effects of livestock grazing on benthic invertebrates from a native grassland ecosystem. Freshwater Biology 48: 347-362.

Shinneman, A. L. C., C. E. Umbanhowar, J. E. Almendinger, M. B. Edlund \& N. Soninkhishig, 2009. Paleolimnologic evidence for recent eutrophication in the Valley of the Great Lakes (Mongolia). Ecosystems 12: 944-960.

Southwood, T. R. E., 1977. Habitat, the templet for ecological strategies. Journal of Animal Ecology 46: 337-365.

Statzner, B. \& L. A. Bêche, 2010. Can biological invertebrate traits resolve effects of multiple stressors on running water ecosystems? Freshwater Biology 55: 80-119.

Statzner, B., B. Bis, S. Dolédec \& P. Usseglio-Polatera, 2001. Perspectives for biomonitoring at large spatial scales: a unified measure for the functional composition of invertebrate communities in European running waters. Basic and Applied Ecology 2: 73-85.

Statzner, B., S. Dolédec \& B. Hugueny, 2004. Biological trait composition of European stream invertebrate communities: assessing the effects of various trait filter types. Ecography 27: 470-488.

Stubblefield, A., S. Chandra, S. Eagan, D. Tuvshinjargal, G. Davaadorzh, D. Gilroy, J. Sampson, J. Thorne, B. Allen \& Z. Hogan, 2005. Impacts of gold mining and land use alterations on the water quality of central Mongolian rivers. Integrated Environmental Assessment and Management 1: 365-373.

ter Braak, C. J. \& P. F. Verdonschot, 1995. Canonical correspondence analysis and related multivariate methods in aquatic ecology. Aquatic Sciences 57: 255-289.

Townsend, C. R. \& A. G. Hildrew, 1994. Species traits in relation to a habitat templet for river systems. Freshwater Biology 31: 265-275.
Tumurchudur, S. \& D. Jadambaa, 2012. Integrated Natural Resource Management in the Baikal Basin Transboundary Ecosystem. UNDP-GEF Project Final Report. http://baikal. iwlearn.org/en/project/project-tender-reports-2012/029bic-conception-for-mongolia. Accessed 15 October 2013.

Usseglio-Polatera, P., M. Bournaud, P. Richoux \& H. Tachet, 2000. Biomonitoring through biological traits of benthic macroinvertebrates: how to use species trait databases? Hydrobiologia 422: 153-162.

Vieira, N. K. M., N. L. Poff, D. M. Carlisle, S. R. Moulton, M. L. Koski \& B. C. Kondratieff, 2006. A database of lotic invertebrate traits for North America. U. S. Geological Survey Data Series 187.US Geological Survey, Reston, Virginia. http://pubs.usgs.gov/ds/ds187/ Accessed 5 October 2013.

Vitousek, P. M., H. A. Mooney, J. Lubchenco \& J. M. Melillo, 1997. Human domination of Earth's ecosystems. Science 277: 494-499.

Wagener, S. M. \& J. D. LaPerriere, 1985. Effects of placer mining on the invertebrate communities of interior Alaska, USA, streams. Freshwater Invertebrate Biology 4: 208-214.

Wiedmann, M. A., M. Aschan, G. Certain, A. Dolgov, M. Greenacre, E. Johannesen, B. Planque \& R. Primicerio, 2014. Functional diversity of the Barents Sea fish community. Marine Ecology Progress Series 495: 205-218.

Wood, P. J. \& P. D. Armitage, 1997. Biological effects of fine sediment in the lotic environment. Environmental Management 21: 203-217.

Yadamsuren, O., B. Hayford, J. Gelhaus, L. Ariuntsetseg, C. Goulden, S. Podenas \& V. Podeniene, 2015. Declines in diversity of crane flies (Diptera: Tipuloidea) indicate impact from grazing by livestock in the Hövsgöl region of Mongolia. Journal of Insect Conservation 19: 465-477.

Zhang, L., D. Liu, S. Liu, Y. Zhang, X. Tong \& B. Wang, 2013. Responses of functional diversity of aquatic insect community to land use change in middle reach of Qianntang River, East China. Chinese Journal of Applied Ecology 24: 2947-2954.

Publisher's Note Springer Nature remains neutral with regard to jurisdictional claims in published maps and institutional affiliations. 